Article

\title{
The Role of Multiwalled Carbon Nanotubes in the Mechanical, Thermal, Rheological, and Electrical Properties of PP/PLA/MWCNTs Nanocomposites
}

\author{
Sohrab Azizi ${ }^{1, *(\mathbb{D}}$, Morteza Azizi ${ }^{2}$ and Maryam Sabetzadeh ${ }^{3}$ \\ 1 Department of automation, production engineering, École de technologie supérieure (ETS), \\ University of Québec, Montreal, QC H3C 1K3, Canada \\ 2 Department of Chemical and Petroleum Engineering, Sharif University of Technology, \\ Tehran 11365-11155, Iran \\ 3 Polymer Group, Department of Chemical Engineering, Isfahan University of Technology, Isfahan 84156, Iran \\ * Correspondence: sohrab.azizi.1@ens.etsmtl.ca
}

Received: 9 June 2019; Accepted: 25 June 2019; Published: 1 July 2019

\begin{abstract}
Polypropylene/polylactic acid (PP/PLA) blend (10-40\% of PLA) and PP/PLA/MWCNTs nanocomposites $(0.5,1$, and $2 \mathrm{wt} \%$ of MWCNTs) were prepared via melt compounding. Scanning electron microscopy revealed a co-continuous PLA phase in the PP/PLA blends with high PLA content. Moreover, the addition of $2 \mathrm{wt} \%$ multi-walled carbon nanotubes (MWCNTs) increased the tensile modulus and tensile strength of the PP/PLA $40 \%$ by $60 \%$ and $95 \%$, respectively. A conductive network was found with the addition of $2 \mathrm{wt} \%$ MWCNTs, where the electrical conductivity of the PP/PLA increased by nine orders of magnitude. At $2 \mathrm{wt} \%$ MWCNTs, a solid network within the composite was characterized by rheological assessment, where the composite turned from nonterminal to terminal behavior. Soil burial testing of the PP/PLA blend within 30 days in natural humus compost soil featured suitable biodegradation, which indicates the PP/PLA blend is as an appropriate candidate for food packing applications.
\end{abstract}

Keywords: blends; mechanical properties; electrical properties; additives; nanocomposites

\section{Introduction}

Since the last decades, polymer blends and composites have been used in different applications due to their significant electrical, mechanical, the rmal, and biodegradation properties. The modification of polymers and composites has led to multiple applications, such as biomedical, energy storage, medical packaging, and food packaging [1-11]. Numerous studies in polymer blending have been conducted with inorganic polymers in which they remain non-degradable in landfills for centuries. Therefore, many studies have been focused on the substitution of the inorganic polymers with biodegradable ones, such as polyethylene glycol, polyethylene oxide, polylactic acid (PLA), polycaprolactone, and many others $[12,13]$. Furthermore, full substitution of petroleum-based polymers with the biodegradable ones is not cost-effective. Therefore, the fabrication of partially biodegradable polymer blends and nanocomposites is more rationale $[10,14]$.

Polypropylene (PP) is a commodity polyolefin with an average molecular weight of 220,000 to 700,000 and a melt flow index range of 0.3 to $1000 \mathrm{~g} / 10 \mathrm{~min}$ [15]. In addition, PP possesses significant chemical resistance in polar solvents, while it is dissolved in nonpolar solvents at high temperatures. The solid semi-crystalline regions in the PP structure melt at melting points around 130 to $170{ }^{\circ} \mathrm{C}$ depending on the degree of crystallinity [16]. The degree of crystallinity of the PP strongly affects the mechanical properties, where a higher crystallinity leads to greater stiffness, yield stress, and flexural strength [15]. 
On the other hand, PLA is known as a biopolymer that is used broadly in tissue engineering, drug delivery systems, food packaging, and (bio) medical applications [17,18]. It exhibits noticeable rigidity $[19,20]$ and moderate gas permeability, which is similar to those of common polymers, such as polystyrene, polyethylene, polyethylene terephthalate, and PP. From the mechanical point of view, PLA behaves as a glassy polymer with high brittleness [21,22], featuring a tensile strength of 30 to $50 \mathrm{MPa}$ and a tensile modulus of 2 to $4 \mathrm{GPa}$. However, the elongation at break of PLA is roughly low, in the range of $1 \%$ to $10 \%$, depending on its molecular weight, enantiomeric purity, and the degree of crystallinity. The main drawback of the PLA relates to its poor toughness, which limits its applications in stressful conditions [14,23-32]. Therefore, to overcome the addressed limitations of PLA, the blending of the PLA with other polymers, such as polyolefins, as well as the composition of inorganic reinforcements with PLA and its blends can lead to the desired properties [33]. For example, the addition of PLA with PP led to an increase of tensile modulus and tensile strength but the elongation at break of PP declined from $500 \%$ to $50 \%$ when $50 \%$ of the PLA was added [34]. Maleic anhydride as a compatibilizer can make a strong bond between the phase components in styrene-ethylene butylene-styrene (SEBS)/propylene (PP) blend and their composites with glass fiber additive, and consequently resulted in a significant increase of the impact strength of the SEBS/PP composites [35]. In addition, the interfacial adhesion between the high-density polyethylene and polystyrene blend was improved using SEBS as compatibilizer, and the ductility of the polymer blend increased remarkably [36].

The role of several additives in the physicochemical properties of PLA composites has been studied [30,31,34,37-41]. For example, multi-walled carbon nanotubes (MWCNTs) are an ideal nanofiller with outstanding electrical, mechanical, and thermal properties [24,25,42-45]. The role of vegetal reed fibers and PP-g-MA compatibilizer on the mechanical properties of PP/PLA composites was investigated by Alain Bourmaud et al. and the outcomes revealed a significant increase of the tensile modulus due to a better filler dispersion and adequate interfacial interactions between the filler and the matrix [46].

The present study is focused on the mechanical, the rmal, rheological, and electrical properties of PP/PLA/MWCNTs nanocomposites. The morphologies of the polymer blend and its composites are investigated by field emission scanning electron microscopy (FE-SEM). The chemical interaction between two immiscible polymers (PP and PLA) is also studied by Fourier-transform infrared spectroscopy (FT-IR). Mechanical properties, such as the tensile strength and tensile modulus, are studied to evaluate the stiffness and elongation at break of the polymer blends and composites. Differential scanning calorimetry (DSC) and thermogravimetric analysis (TGA) are also conducted to assess the thermal properties of the prepared test specimens. The electrical properties of the nanocomposites are investigated across the disk test specimens. Eventually, the biodegradability of the blends is studied via the soil burial test.

\section{Experimental}

\subsection{Materials}

PP with a density of $0.81 \mathrm{~g} / \mathrm{cm}^{3}$ and a melt flow index (MFI) of $3.2 \mathrm{~g} / 10 \mathrm{~min}$ was supplied by Jam Petrochemical Co. PLA with a melting point of $158^{\circ} \mathrm{C}$, MFI of $17 \mathrm{~g} / 10 \mathrm{~min}$, density of $1.3 \mathrm{~g} / \mathrm{cm}^{3}$, and molecular weight of $195,000 \mathrm{~g} / \mathrm{mol}$ was supplied by Shanghai Jiaofu new materials technology Company with the trademark of JOYFUL. The MWCNTs filler was purchased from NANOCYLTM NC7000 with a surface area of 250 to $300 \mathrm{~m}^{2} / \mathrm{g}$, average diameter of $9.5 \mathrm{~nm}$, and average length of $1.5 \mu \mathrm{m}$ with a carbon purity of $90 \%$. The PP-g-MA copolymer with $16 \mathrm{mg} \mathrm{KOH} / \mathrm{g}$, MA content of $1 \mathrm{wt} \%$, melt flow rate of $5.1 \mathrm{~g} / 10 \mathrm{~min}$, and molecular weight of 52,000 was used as a reactive compatibilizer, provided by Aria polymer pishgam Company (Isfahan, Iran). All materials were used as received. 


\subsection{Material Compounding and Sample Preparation}

The MWCNTs, PP, and PLA materials were dried for $24 \mathrm{~h}$ at $70{ }^{\circ} \mathrm{C}$ in an oven to remove the residue of humidity before the compounding. Different PP/PLA blends consisting of several PLA contents and a chosen PP/PLA blend composite with different amounts of MWCNTs were prepared (Table 1). The diameter of the screw was $25 \mathrm{~mm}$ and the length to diameter ratio (L/D) was 40 . The adjusted temperature profile along the melting zone was 180 to $210^{\circ} \mathrm{C}$ (from the feed zone to die). Different PLA loadings were chosen $(10,20,30$, and $40 \mathrm{wt} \%)$, and $0.5,1$, and $2 \mathrm{wt} \%$ of the MWCNTs were added to the chosen blend to prepare the nanocomposites. The continuously extruded polymers were cooled with a cold-water trough and subsequently pelletized. The pellets were then compression molded into $1 \mathrm{~mm}$ thick sheets using a hydraulic press machine (Toyoseiki, model $\mathrm{WCH}$, Tokyo, Japan) at $170{ }^{\circ} \mathrm{C}$ with a pressure of $10 \mathrm{MPa}$. The test specimens for mechanical analysis were prepared with an injection molding machine (Iman Machin, PAYA).

Table 1. The labeled samples with the ratio of the polymers in the blend, as well as the filler content in the nanocomposites.

\begin{tabular}{ccccc}
\hline Labeled Sample & $\begin{array}{c}\text { PP } \\
\mathbf{( w t \% )}\end{array}$ & $\begin{array}{c}\text { PLA } \\
\mathbf{( w t \% )}\end{array}$ & $\begin{array}{c}\text { PP-g-MA } \\
(\mathbf{w t} \% \mathbf{o f} \text { PLA) }\end{array}$ & $\begin{array}{c}\text { MWCNTs } \\
\text { (wt\% of Total Sample) }\end{array}$ \\
\hline PP & 100 & 0 & 0 & 0 \\
PLA & 0 & 100 & 0 & 0 \\
PP/PLA10\% & 90 & 10 & 1 & 0 \\
PP/PLA20\% & 80 & 20 & 2 & 0 \\
PP/PLA30\% & 70 & 30 & 3 & 0 \\
PP/PLA40\% & 60 & 40 & 4 & 0 \\
PP/PLA40/MWCNTs 0.5\% & 60 & 40 & 4 & 1 \\
PP/PLA40/MWCNTs 1\% & 60 & 40 & 4 & 2 \\
PP/PLA40/MWCNTs 2\% & 60 & 40 & 4 & \\
\hline
\end{tabular}

\subsection{Characterizations of Blends and Nanocomposites}

\subsubsection{Field Emission-Scanning Electron Microscopy (FE-SEM)}

The morphology of the PP/PLA blends and PP/PLA/MWCNTs nanocomposites were studied by a field emission scanning electron microscope (FE-SEM) (TESCAN, model MIRA3, Czech Republic). Each sample was cryo-fractured using liquid nitrogen at $-100^{\circ} \mathrm{C}$ and then coated with a $3 \mathrm{~nm}$ gold layer.

\subsubsection{Fourier-Transform Infrared Spectroscopy (FTIR)}

FTIR characterization was performed using a FT-IR spectrophotometer (Perkin-Elmer, model Spectrum RX 1, Boston, MA, USA) in the 400 to $4000 \mathrm{~cm}^{-1}$ wavenumber range with a resolution of $4.0 \mathrm{~cm}^{-1}$ and an average number of scans of 120 .

\subsubsection{Differential Scanning Calorimetry (DSC)}

Thermal properties of the samples, including the crystalline temperature $\left(T_{c}\right)$ and melting temperature $\left(\mathrm{T}_{\mathrm{m}}\right)$, were measured by a differential scanning calorimeter (Perkin-Elmer DSC-6). Each sample was heated from 60 to $200^{\circ} \mathrm{C}$ with a heating ramp of $10^{\circ} \mathrm{C} / \mathrm{min}$ and holding for $1 \mathrm{~min}$ at this temperature. Consequently, the sample was cooled down to $60^{\circ} \mathrm{C}$ at the rate of $10^{\circ} \mathrm{C} / \mathrm{min}$, and finally, the sample was heated again from 60 to $200^{\circ} \mathrm{C}$ at the same heating ramp. The data from the first cooling and second heating step were acquired for the DSC analysis. The degree of crystallinity of the PP/PLA blend and PP/PLA/MWCNTs composites was calculated according to the Equation (1) [47]:

$$
X_{c}=\frac{\Delta H_{C}}{(1-\varphi) \Delta H_{m}} \times 100
$$


where $\Delta H_{m}$ is the fusion heat of PP in the $100 \%$ crystalline state $\left(\Delta H_{C}=209 \mathrm{~J} / \mathrm{g}\right)$ [47] and $\varphi$ is the weight fraction of the filler in the composite.

\subsubsection{Thermogravimetric Analysis}

The thermal stability of the PP/PLA blends and PP/PLA/MWCNTs composites was examined by a thermal gravimetric analysis/differential thermal analysis (TGA/DTA )instrument (Perkin Elmer). The measurement was conducted with a sample around 10 to $15 \mathrm{mg}$, from 200 to $600{ }^{\circ} \mathrm{C}$ with a ramp of $20^{\circ} \mathrm{C} / \mathrm{min}$ under an argon atmosphere.

\subsubsection{Mechanical Tests}

Mechanical properties (tensile strength, tensile modulus, and elongation at break) were investigated by a universal testing machine, (Zwick/Roell, Ulm, Germany) according to the ISO 527-2 standard test method at room temperature. The crosshead speed was $50 \mathrm{~mm} / \mathrm{min}$ in all tests. Five replicates were tested for each sample and the average values were reported.

\subsubsection{Rheological Measurements}

The dynamic rheological properties of the PP/PLA blends and PP/PLA40/MWCNTs nanocomposites were measured by a rheometer (MCR301, Anton Paar GmbH, Graz, Austria) using parallel plate geometry. Measurements were carried out in the mode of frequency sweep in the range of 0.01 to $100(\mathrm{rad} / \mathrm{s})$ with a fix strain amplitude of $1 \%$ at the temperature of $185^{\circ} \mathrm{C}$.

\subsubsection{Electrical Properties}

The AC electrical properties of the PP/PLA/MWCNTs nanocomposites were measured using broadband dielectric spectroscopy (novocontrol, Montabaur, Germany) at room temperature over a wide range of frequencies from 0.1 to $1 \mathrm{MHz}$. A disk sample with a thickness of $\sim 1 \mathrm{~mm}$ and a diameter of $30 \mathrm{~mm}$ was placed between two electrodes of brass and subjected to a 3 Vrms electric field.

\subsubsection{Blend Biodegradability}

A soil burial test was used to measure the released $\mathrm{CO}_{2}$ content $\left(\mathrm{mg} \mathrm{CO}_{2} / \mathrm{g}\right.$ dry soil) resulting from an aerobic biodegradation for the blend samples, in accordance with the ASTM D 5988 test method. First, $2 \times 3 \mathrm{~cm}^{2}$ sheets were inserted into $200 \mathrm{mg}$ soil with the specific field capacity (water content) of $50 \%$ to $60 \%$. In total, $20 \mathrm{~mL}$ of $0.5 \mathrm{~N} \mathrm{NaOH}$ solution in a $50 \mathrm{~mL}$ beaker, and $50 \mathrm{~mL}$ of distilled water in a $100 \mathrm{~mL}$ beaker were placed in the desiccator. The $\mathrm{NaOH}$ solution was utilized to trap the released $\mathrm{CO}_{2}$. Then, it was sealed and maintained in a dark cabinet at $28^{\circ} \mathrm{C}$. At the predetermined time points, the $\mathrm{NaOH}$ solution was titrated by $0.1 \mathrm{~N} \mathrm{HCl}$ acid and phenolphthalein as the indicator and two or three droplets of $\mathrm{BaCl}_{2}$ solution, which facilitates the titration process. The released $\mathrm{CO}_{2}$ in the PP/PLA systems was measured using Equation (2) [48]:

$$
\mathrm{CO}_{2}(\mathrm{mg}) / \operatorname{dry} \operatorname{soil}(\mathrm{g})=\frac{\left(\mathrm{V}_{0}-\mathrm{V}_{1}\right) \cdot \mathrm{N}}{\mathrm{W}_{\mathrm{d}}} \times 22,
$$

where $V_{0}$ and $V_{1}$ are the volumes of consumed acid $(\mathrm{mL})$ in the control and studied samples, respectively. Also, $\mathrm{N}, \mathrm{W}_{\mathrm{d}}$, and the number of 22 were the normality of the used acid, the weight of dried soil, and the weight $(\mathrm{mg})$ of one equivalent of $\mathrm{CO}_{2}$, respectively.

\section{Results and Discussion}

\subsection{Characterization and Morphology}

The FE-SEM morphology images of the PP/PLA blends are shown in Figure 1. For the PP/PLA10\%, the PLA spherical-domains were more and less uniformly dispersed throughout the PP matrix, but due 
to the greater viscosity of PP, the PLA spherical-domains were observed as being nicely dispersed and aggregated (Figure 1c). The loading of more PLA content was found to form a co-continuous PLA phase within the PP/PLA, as can be seen in Figure 1d-f. The formation of the co-continuoues blend can be attributed to the effect of compatibilizer (PP-g-MA) on the interfacial interaction between two immiscible polymers and better compatibility of the constituents. In addition, the increase of the PLA content led to smaller-sized PLA spherical-domains and a greater polydispersity (Figure 1f). Then, this causes a higher compatibility between the PP and PLA polymers.
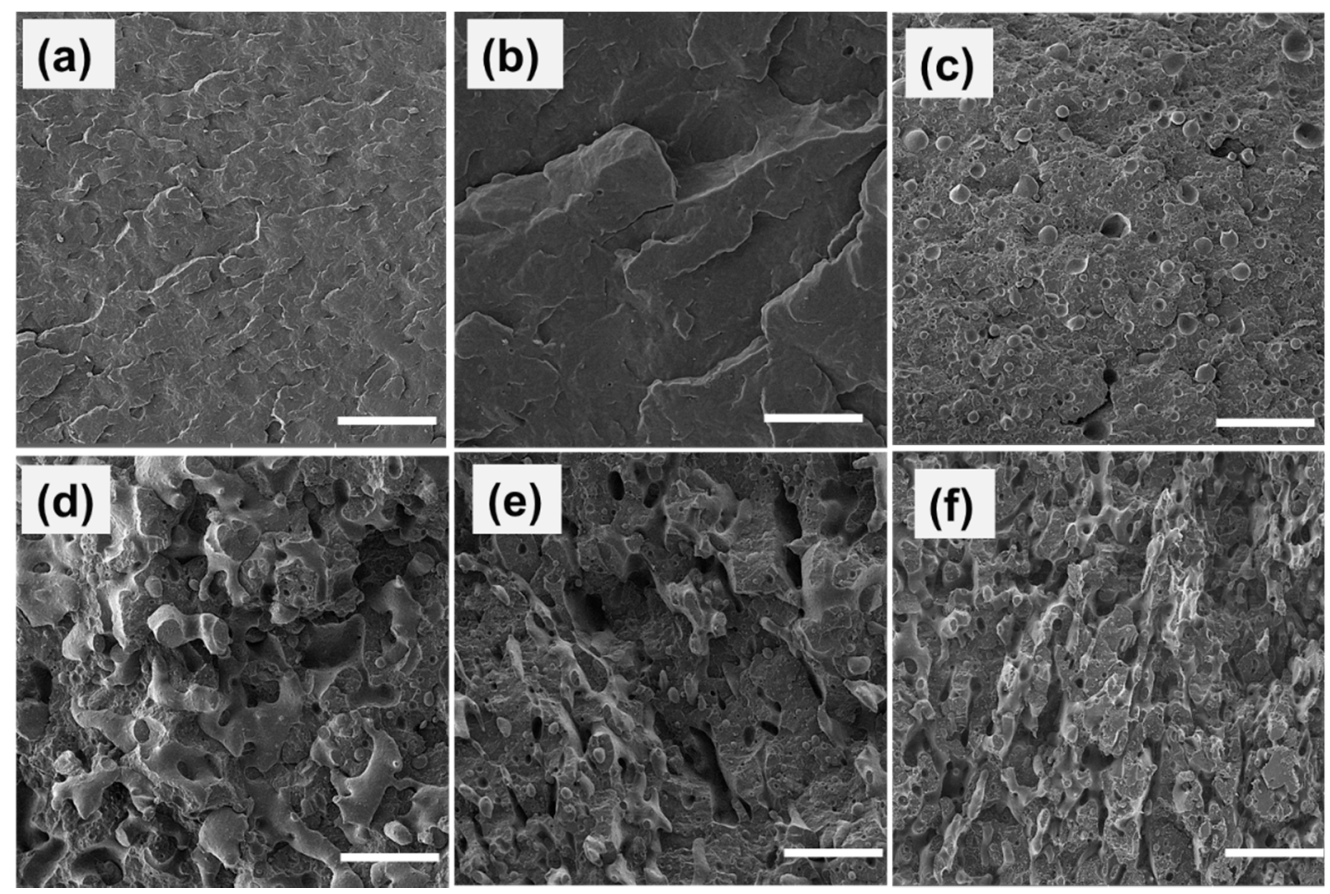

Figure 1. The FE-SEM micrographs of (a) PP, (b) PLA, (c) PP/PLA10\%, (d) PP/PLA20\%, (e) PP/PLA30\%, and (f) PP/PLA40\%. The scale bar represents $100 \mu \mathrm{m}$.

The dispersion of the MWCNT filler in the PP/PLA40/MWCNTs is shown in Figure 2. The FE-SEM images depicted a good dispersion of MWCNTs within the PP/PLA matrix. It is distinguishable that most of the individual MWCNTs were fully dispersed within the composite's structure. Furthermore, MWCNTs at the $2 \mathrm{wt} \%$ addition (Figure 2c) were randomly aligned, locally forming interconnecting structures. In addition, the nanostructure morphology of the composites revealed that MWCNTs agglomeration did not take place in the PP/PLA/MWCNTs matrix.
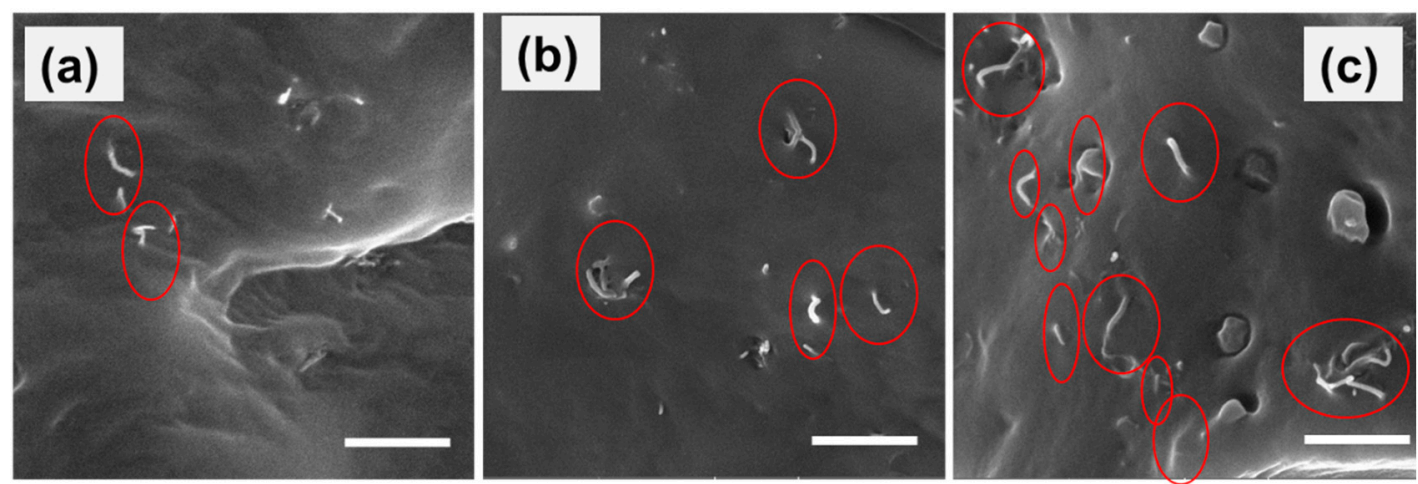

Figure 2. FE-SEM images of (a) PP/PLA40/MWCNTs 0.5\%, (b) PP/PLA40/MWCNTs 1\%, and (c) PP/ PLA40/MWCNTs $2 \%$. The scale bar equals $500 \mathrm{~nm}$. 


\subsection{FT-IR Spectroscopy Analysis}

FT-IR spectroscopy was used to investigate the potential interaction of PP-g-MA with PP and PLA. Figure 3 shows the FT-IR spectra of the PP/PLA blends, compared to the PP and PLA. The PP spectra revealed several peaks at 2950 to 2838,1450 to 1453 , and $1376 \mathrm{~cm}^{-1}$ that were designated to C-H stretching, $-\mathrm{CH}_{3}$ bending, and $\mathrm{C}-\mathrm{H}$ bending, respectively. The PLA spectra showed three peaks at 1755 , 1290 , and $1195 \mathrm{~cm}^{-1}$ corresponding to $\mathrm{C}=\mathrm{O}$ stretching, symmetric $\mathrm{C}-\mathrm{O}-\mathrm{C}$ stretching, and asymmetric $\mathrm{CH}_{3}$, respectively. A characteristic peak appeared at $1749 \mathrm{~cm}^{-1}$ for all PP/PLA blends, which is assigned to the stretching of the ester group (-COO) in which the chemical interaction of the anhydride group of PP-g-MA with the carbonyl group existing in PLA formed a new linkage, indicating the compatibility of PP/PLA blends. By an increase of the PLA content, the intensity of ester linkage transmission bands increased continuously, which is associated with the higher content of ester linkage formation and better compatibility.

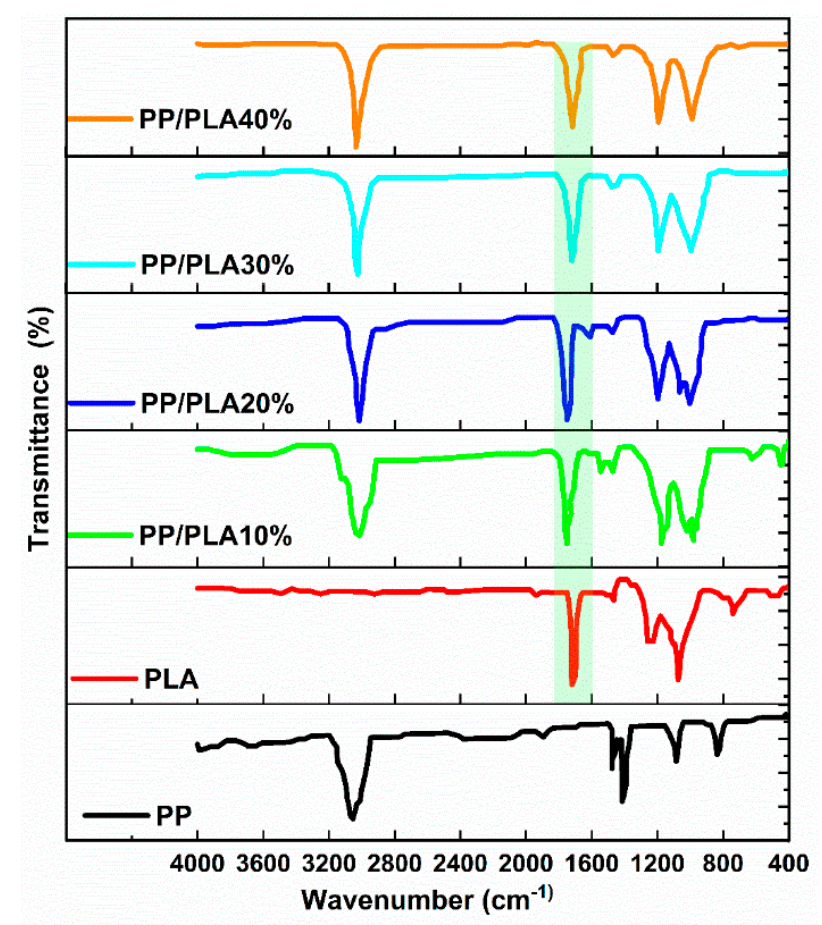

Figure 3. The FT-IR spectra of PP, PLA, and PP/PLA blends over the wavelength range from 400 to $4000 \mathrm{~s}^{-1}$.

\subsection{Thermal Properties}

To investigate the thermal properties of PP/PLA blends and PP/PLA40/MWCNTs nanocomposites, a DSC experiment was carried out, and the heating and cooling thermograms are shown in Figure 4. As can be seen in the quenching thermograms, no crystalline peak was detected for the PLA polymer, while the PP displayed a remarkable peak at $\sim 115^{\circ} \mathrm{C}$. The crystalline temperature for the PP/PLA blends was detected with no significant change, but the MWCNTs nanofillers acted as a nucleating agent in the nanocomposite structure, where a slightly higher fusion's enthalpy was found for the nanocomposites (Figure 4a). Both PP and PLA samples showed approximately close melting points at $159^{\circ} \mathrm{C}$ and $158^{\circ} \mathrm{C}$, respectively. Polymer blending of PP with PLA depicted a fairly constant melting point. A slight increase in the melting point of PP/PLA40/MWCNTs composites with the addition of MWCNTs filler (Table 2) was detected due to possible physical interactions between the PP/PLA blend and the filler (Figure 4b) [8]. The degree of crystallinity of the PP/PLA blend and its composites with MWCNTs is listed in Table 2, and somehow no significant change occurred in the degree of crystallinity of the test specimens. 

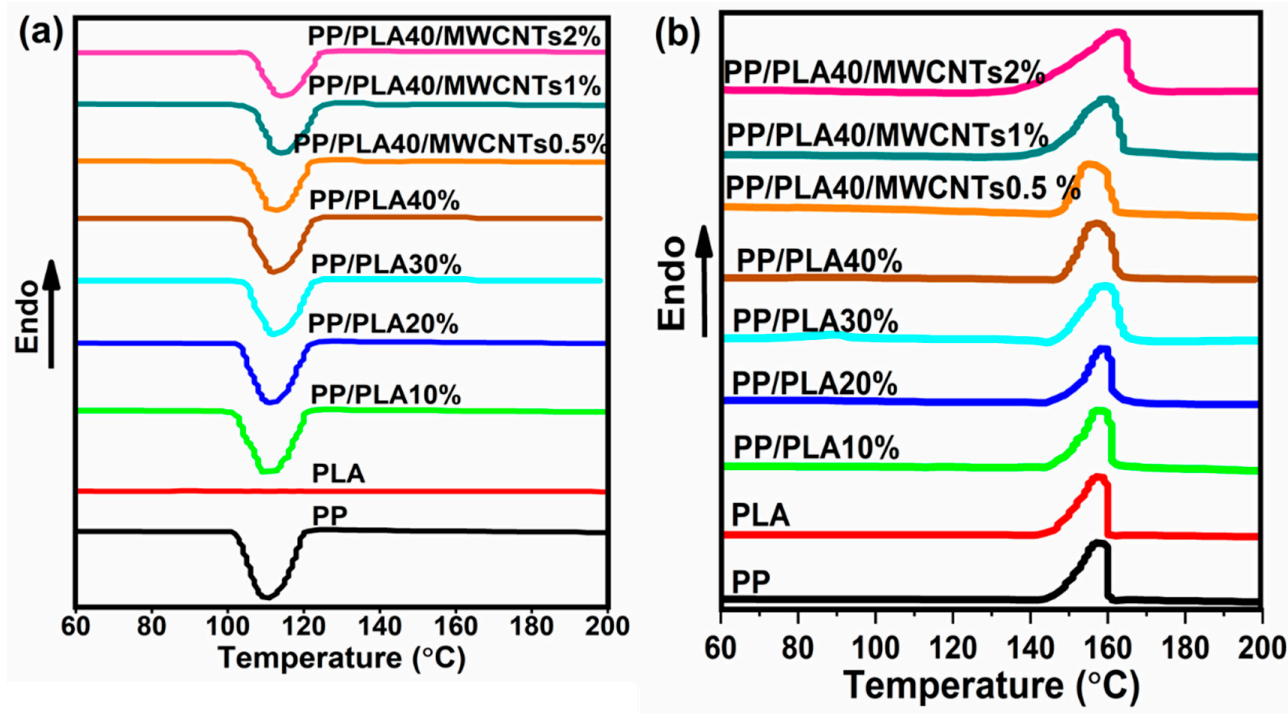

Figure 4. Differential scanning calorimetry (DSC) thermograms of PP, PLA, PP/PLA blends, and PP/ PLA40/MWCNTs composites, (a) cooling and (b) second heating step.

\subsection{Thermogravimetric Analysis (TGA) Results}

The thermal stability of the PP/PLA blends and PP/PLA/MWCNTs nanocomposites were investigated with TGA, and the results are shown in Figure 5 and Table 2. As indicated, the onset temperature of the PP/PLA blends was found to be slightly greater than the PLA's. As the temperature increased, the first significant weight loss was revealed, which can be ascribed to the vanishing of the ester groups in the PLA structure. Another significant weight loss was observed, starting at $\sim 380^{\circ} \mathrm{C}$, which can be attributed to the decomposition of the PP polymer. The loading of MWCNTs increased the onset thermal stability of PP/PLA $40 \%$, indicating the greater thermal stability of the nanofiller, as well as the possible physical interactions between PP and PLA with the nanofiller [49,50]. The accuracy of the filler content in the nanocomposites was examined by TGA, as indicated in Table 2, and the remaining ash at $500{ }^{\circ} \mathrm{C}$ to some extent was equal to the corresponding prepared nanocomposites.

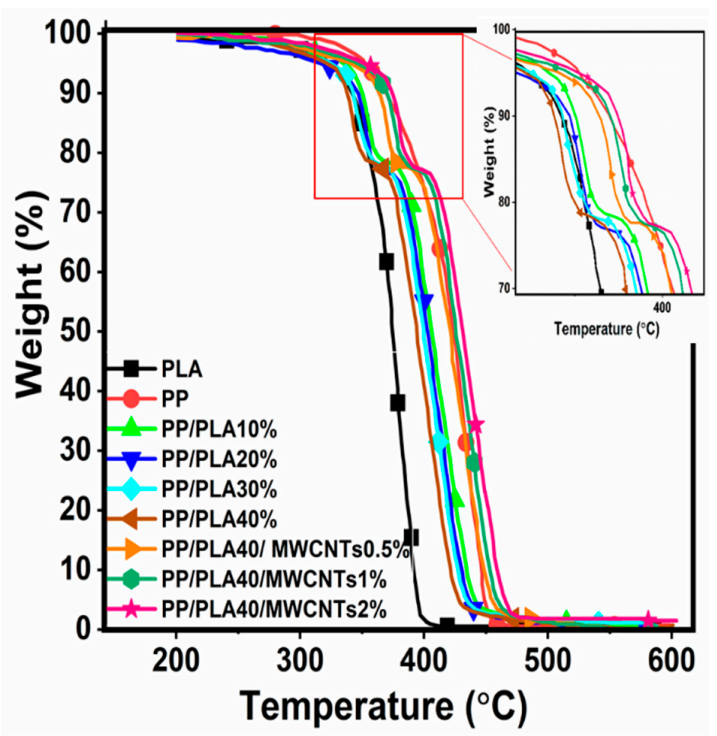

Figure 5. The thermogravimetric analysis (TGA) plot of the PP/PLA blend and PP/PLA40/MWCNTs nanocomposites at temperatures from 200 to $600^{\circ} \mathrm{C}$. 
Table 2. DSC and TGA results: crystalline point, melting point, $\mathrm{T}_{5 \%}\left({ }^{\circ} \mathrm{C}\right), \mathrm{T}_{50 \%} 5 \%$, and the remaining ash at $500\left({ }^{\circ} \mathrm{C}\right)$ of the PP, PLA, PP/PLA blends, and PP/PLA/MWCNTs nanocomposites.

\begin{tabular}{ccccccc}
\hline & \multicolumn{3}{c}{ DSC } & \multicolumn{3}{c}{ TGA } \\
\cline { 2 - 7 } Sample & $\begin{array}{c}\mathbf{T}_{\mathbf{c}} \\
\left({ }^{\circ} \mathbf{C}\right)\end{array}$ & $\begin{array}{c}\mathbf{T}_{\mathbf{m}} \\
\left({ }^{\circ} \mathbf{C}\right)\end{array}$ & $\begin{array}{c}\mathbf{X c}_{\mathbf{c}} \\
(\mathbf{\%})\end{array}$ & $\begin{array}{c}\mathbf{T}_{\mathbf{5} \%} \\
\left({ }^{\circ} \mathbf{C}\right)\end{array}$ & $\begin{array}{c}\mathbf{T}_{\mathbf{5 0} \%} \\
\left({ }^{\circ} \mathbf{C}\right)\end{array}$ & $\begin{array}{c}\text { Ash Percent at 500 } \\
\left({ }^{\circ} \mathbf{C}\right)\end{array}$ \\
\hline PP & 115 & 159 & 50.5 & 340 & 450 & 0 \\
PLA & - & 158 & - & 290 & 390 & 0 \\
PP/PLA10\% & 117 & 159 & 50.1 & 293 & 420 & 0 \\
PP/PLA20\% & 117 & 159 & 49.8 & 295 & 423 & 0 \\
PP/PLA30\% & 117 & 158 & 49.6 & 296 & 426 & 0 \\
PP/PLA40\% & 117 & 158 & 49.7 & 350 & 428 & 0 \\
PP/PLA40/MWCNTs 0.5\% & 118 & 161 & 49.8 & 352 & 445 & 0.4 \\
PP/PLA40/MWCNTs 1\% & 118 & 162 & 50.3 & 353 & 447 & 0.9 \\
PP/PLA40/MWCNTs 2\% & 118 & 163 & 50.5 & 355 & 448 & 1.9 \\
\hline
\end{tabular}

\subsection{Mechanical Properties}

The role of the PLA in the PP/PLA blends and MWCNTs nanofiller in the PP/PLA40/MWCNTs nanocomposites was characterized in terms of the mechanical properties. The stress at break, tensile modulus, and elongation at break of the blends and nanocomposites are shown in Figures $6 \mathrm{a}-\mathrm{c}$ and $7 \mathrm{a}-\mathrm{c}$, respectively. The results showed that the stress at break and tensile strength of PP/PLA blends improved with the increase of the PLA content thanks to the higher tensile modulus of the PLA, compared to the PP matrix [21]. The compatibilizer bridged two immiscible polymers, forming a strong chemical bond, as proven by the FT-IR analysis. In addition, the SEM images showed further interaction between PP and PLA phases happened as the size of minor domains (PLA) decreased. Also, the addition of a higher PLA content (20,30 and $40 \mathrm{wt} \%$ ) in the PP/PLA blend resulted in the formation of a co-continuous phase of PLA (see Figure 1d-f). Thus, as observed, the mechanical properties of polymer blends were strongly intensified with greater intrinsic properties of PLA, increasing the PLA content as well as the existence of the compatibilizer. However, the elongation at break of the PP/PLA blends revealed the opposite trend with increasing the PLA contents due to the low elongation at break of PLA compared to that of PP.
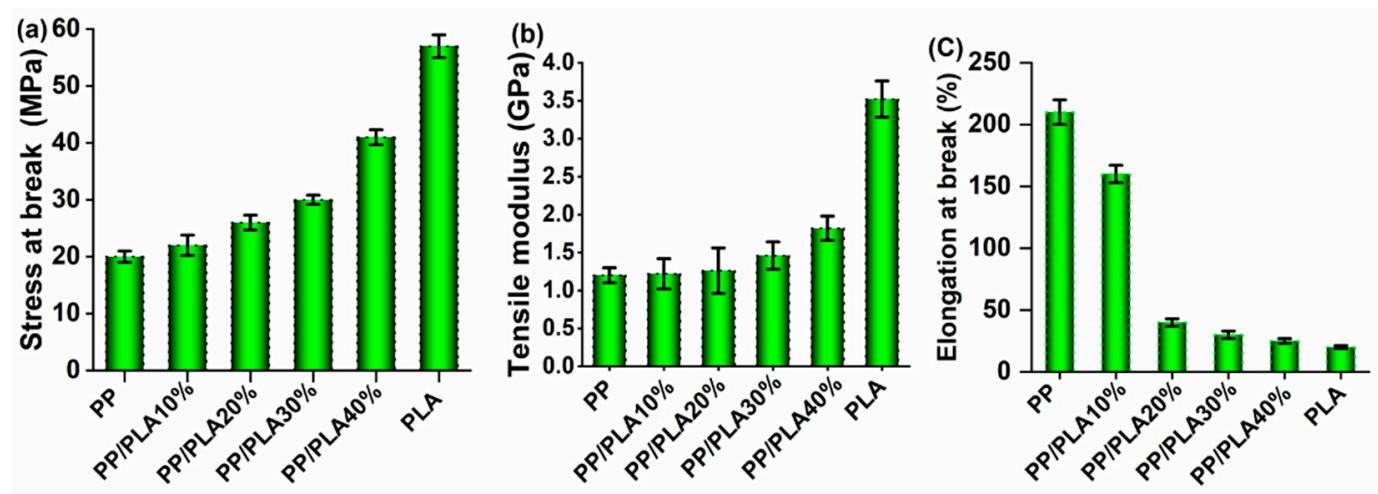

Figure 6. Mechanical properties of (a) stress at break, (b) tensile modulus, and (c) elongation at break of PP, PP/PLA blends, and PLA.

The addition of MWCNTs filler $(0.5,1$, and $2 \mathrm{wt} \%)$ increased the tensile modulus and stress at break of the test specimens continuously. This is explained by the reinforcement effect of MWCNTs fillers in the nanocomposite structure and noticeable friction between the nanotubes and polymer chains. Thus, the addition of $2 \mathrm{wt} \%$ of the MWCNTs increased the tensile modulus of PP/PLA40/MWCNTs up to $60 \%$. Furthermore, noticeable improvement of tensile strengths $(\sim 90 \%)$ was observed as $2 \mathrm{wt} \%$ of the MWCNTs was composed of the PP/PLA $40 \%$. The elongation at break of PP/PLA/MWCNTs 
composites also increased with the addition of MWCNTs nanofiller, which can be attributed to the interfacial adhesion between the PP/PLA and MWCNTs (Figure 7) [51].
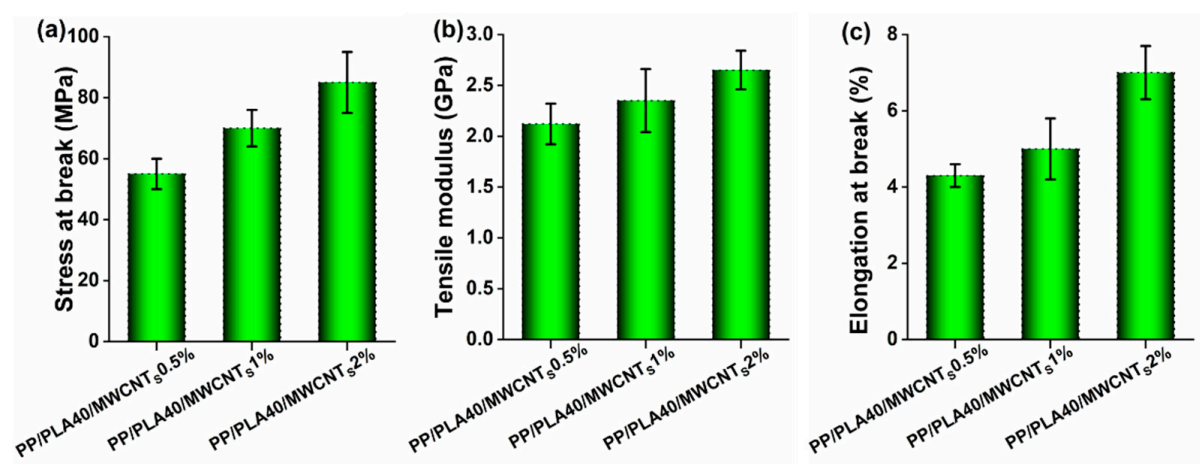

Figure 7. Mechanical properties of PP/PLA40/MWCNTs nanocomposites: (a) the tensile strength,

(b) tensile modules, and (c) elongation at break.

\subsection{Rheology Properties}

A small amplitude oscillatory shear (SAOS) test was carried out to obtain a broader overview of the solid network formation within the composites. The rheological parameters, such as the dynamic storage modulus $\left(G^{\prime}\right)$, and complex viscosity $\left(\eta^{*}\right)$, of PP/PLA $40 \%$ and its nanocomposites with $0.5,1$, and $2 \mathrm{wt} \%$ MWCNTs content are shown in Figure 8a,b. As can be seen, the polymer chains in the PP/PLA $40 \%$ and nanocomposite at low filler contents $(0.5 \mathrm{wt} \%)$ were fully relaxed and indicated a non-terminal behavior due to deformation of the interface under oscillatory shear flow. PP/PLA40/MWCNTs 1\% was found to show a higher storage modulus and complex viscosity than the PP/PLA blend and PP/PLA40/MWCNTs $0.5 \%$ due to the formation of a partial filler network within the composite. However, with the addition of more MWCNTs filler, the polymer chains in PP/PLA40/MWCNTs $2 \%$ were further restrained and restricted, leading to a plateau region at the low frequency, which is attributed to the formation of the MWCNTs network filler [52]. The former sign is known as terminal behavior in composites, which gives an overall clue regarding the percolation threshold in the composite structure [52]. The addition of MWCNTs led to an increase in the viscosity of the PP/PLA blends. The main reason behind this observation could be the formation of interconnected networks and decreased mobility of the chains [53].
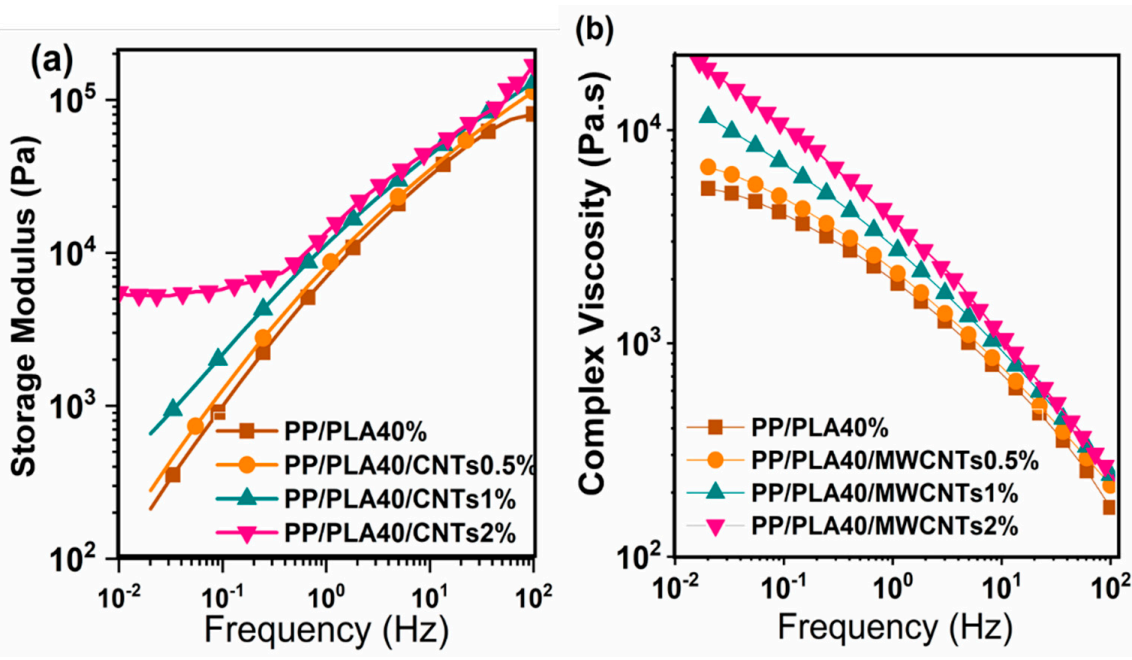

Figure 8. Rheological properties; (a) dynamic storage modulus $\left(\mathrm{G}^{\prime}\right)$ and $(\mathbf{b})$ complex viscosity $\left(\eta^{*}\right)$ of $\mathrm{PP} / \mathrm{PLA} 40 \%$ and its nanocomposite with $0.5,1$, and $2 \mathrm{wt} \%$ MWCNTs filler over the frequency range of 0.01 to $100 \mathrm{~Hz}$. 


\subsection{Electrical Properties}

The AC electric responses (real and imaginary permittivity) of the PP/PLA40\% and PP/PLA40/ MWCNTs composites are shown in Figure 9. A relaxation peak ( $\alpha$-relaxation peak) at around $10 \mathrm{kHz}$ appeared that is addressed by segmental motions in the PLA polymer when PP/PLA40\% was subjected to an electric field [54]. The loading of MWCNTs nanofiller increased the complex permittivity of the nanocomposites. When the MWCNTs content reached $2 \mathrm{wt} \%$ (percolation threshold), a significant rise in the electrical conductivity was found, which is attributed to the charge carried by the electric network within the PP/PLA40/MWCNTs nanocomposites [55-59]. Therefore, as seen in Figure 9b, the imaginary permittivity of the electric response was dominated by DC conductivity and led to an increase of nine orders of magnitude from $10^{-10}$ for the PP/PLA blend to $10^{-1}(\mathrm{~S} / \mathrm{m})$ for the PP/PLA40/MWCNTs $\%$ (Figure 10).
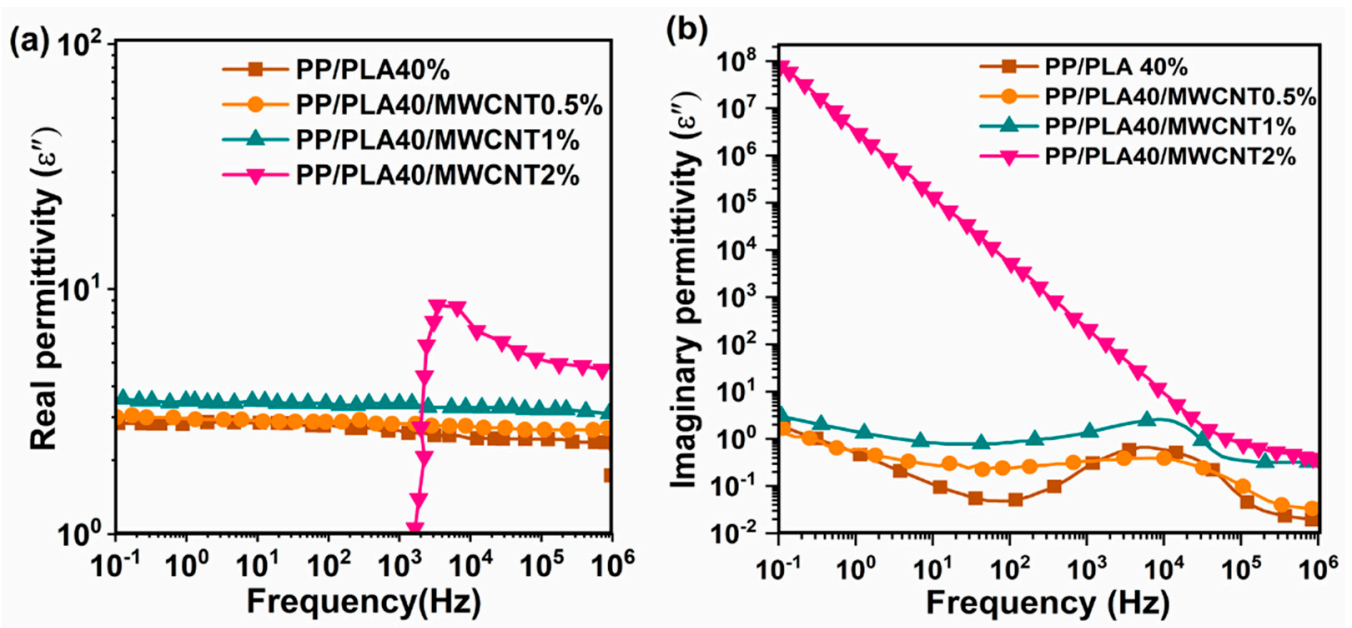

Figure 9. The electric response of PP/PLA40/MWCNTs composites: (a) real permittivity and (b) imaginary permittivity of nanocomposites at room temperature at the range of frequency, $0.1-1 \mathrm{MHz}$.

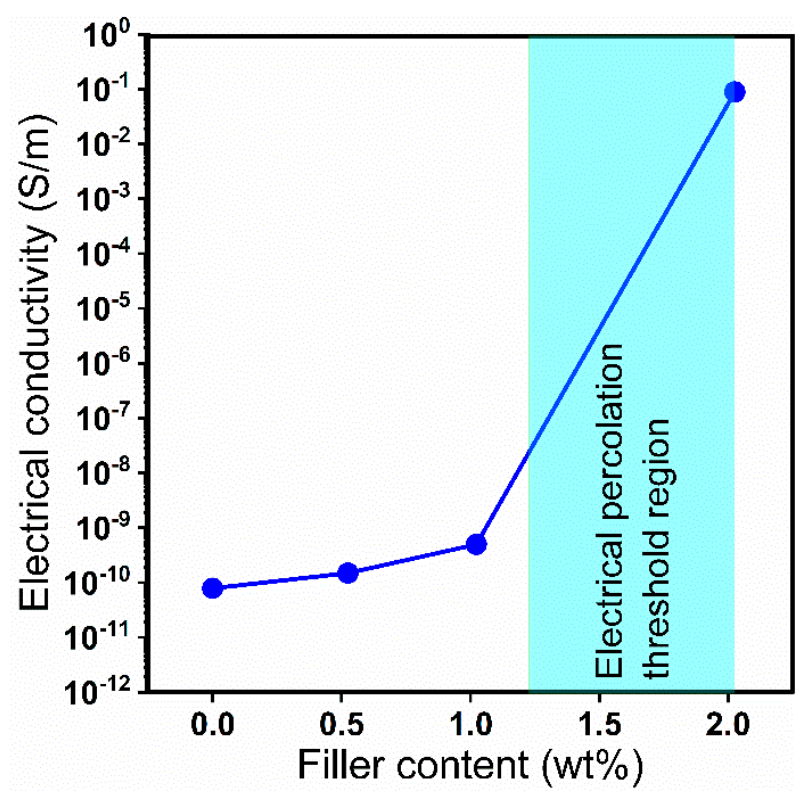

Figure 10. The electrical conductivity of PP/PLA40/MWCNTs nanocomposites as a function of the filler content. 


\subsection{Biodegradability of Polypropylene/Polylactic Acid (PP/PLA) Blends}

The biodegradation of PP/PLA blends via weight loss of the PP/PLA samples was carried out using a long-time soil burial test. Usually, those polymer blends do not reveal a mass loss of up to 39 weeks $( \pm 5 \%)$. So, it is necessary to investigate the biodegradability of samples qualitatively (visually) or quantitatively (indirectly). The biodegradability of the PP/PLA blends (Figure 11) was measured by calculating the amount of the released $\mathrm{CO}_{2}$ from the PLA degradation. The soil burial degradation of the PLA, as reported in previous studies [42,60], followed by two consecutive steps. First, the PLA chains with the higher molecular weight were hydrolyzed [61] and second, the polymer chains were broken down into the lower molecular weight chains. Several parameters, such as acidic or basic moieties, moisture, or temperature, can accelerate the biodegradation process. Thus, to boost the hydrolysis, some microorganisms existing within the compost could boost the degradation, possibly by the hydrolysis disintegrating the ester groups and, ultimately, transforming the shorter chains to the water, $\mathrm{CO}_{2}$, and humus [62]. The PP/PLA40\% blend showed the highest biodegradation rate due to the higher content of the biodegradable PLA polymer. The results demonstrated that the process of biodegradation was not completely linear, and it obeyed an exponential trend. We did not study the biodegradation of PP/PLA/MWCNTS nanocomposites as one of our aims in this study was to use this blend in food packaging applications. As shown previously, the MWCNTs have toxic properties, which can inhibit their application in food packaging [63,64].

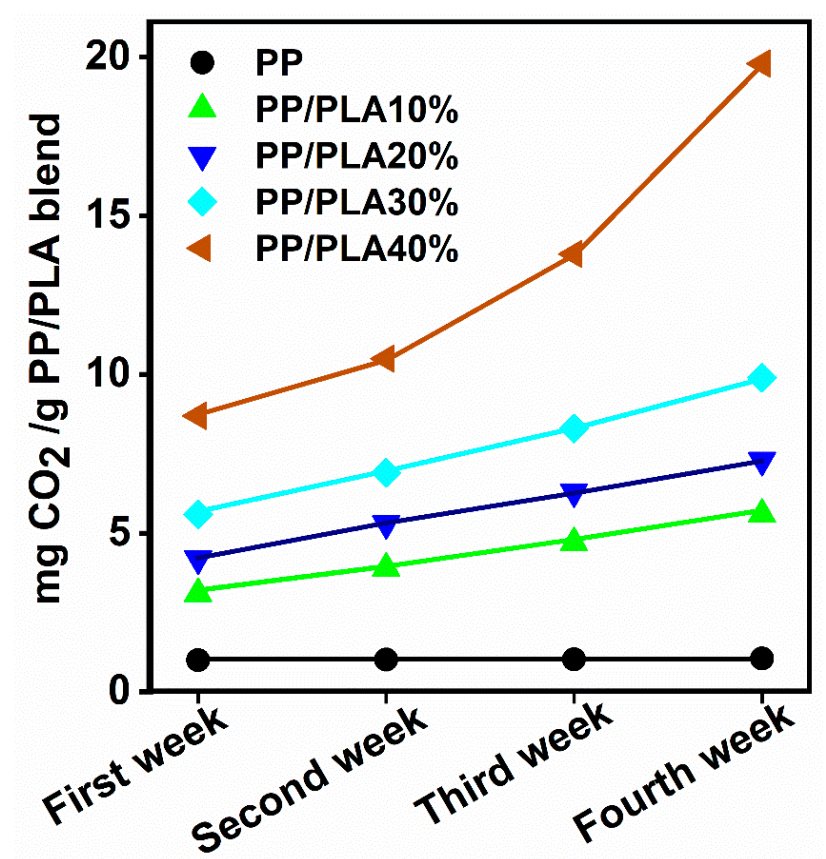

Figure 11. $\mathrm{CO}_{2}$ release versus time (week) as a criterion of the biodegradability of PP and PP/PLA blends.

\section{Conclusions}

In the present work, PP was blended with different contents of PLA and one polymer blend of PP/PLA was tailored to MWCNTs. The findings revealed that the PLA part of the PP/PLA blend can be degraded when it is subjected to a moisturized environment. Thus, this blend is suggested as a suitable biodegradable candidate for food packaging applications. The PP/PLA40\% blend was chosen to improve its mechanical, electrical, and thermal properties via the addition of MWCNTs. The outcomes depicted a significant increase in the tensile strength (approximately 95\%) for the PP/PLA40/MWCNTs2\% with respect to the PP/PLA40\%. The loading of $2 \mathrm{wt} \%$ of MWCNTs filler increased the electrical conductivity of the composites remarkably and this change was characterized by observing a percolation in the composite at this filler content. 
Author Contributions: Investigation, S.A.; Project administration, S.A.; Writing—original draft, S.A., M.A., and M.S.

Funding: This research received no external funding.

Acknowledgments: The authors would like to thank Phuong Nguyen-Tri (École de technologie supérieure, Université du Québec).

Conflicts of Interest: The authors declare no conflict of interest.

\section{References}

1. Mohamad, I.N.; Rohani, R.; Mastar, M.S.; Nor, M.T.M.; Jahim, J.M. Permeation properties of polymeric membranes for biohydrogen purification. Int. J. Hydrogen Energy 2016, 41, 4474-4488. [CrossRef]

2. Azizi, M.; Ramazani, S.A.A.; Etemadi, M.H.; Shirzaei, S.E. Simulation of viscoelastic fluid flows in expansion geometry using finite volume approach. Chin. J. Polym. Sci. 2013, 31, 1599-1612. [CrossRef]

3. Mousavi, S.A. CO2/H2 separation using a highly permeable polyurethane membrane: Molecular dynamics simulation. J. Mol. Struct. 2015, 1100, 401-414.

4. Wu, D.; Wu, L.; Sun, Y.; Zhang, M. Rheological properties and crystallization behavior of multi-walled carbon nanotube/poly (E-caprolactone) composites. J. Polym. Sci. Part B Polym. Phys. 2007, 45, 3137-3147. [CrossRef]

5. Seddigh, E.; Azizi, M.; Sani, E.S.; Mohebbi-Kalhori, D. Investigation of Poly (ether-b-amide)/Nanosilica Membranes for CO2/CH4 Separation. Chin. J. Polym. Sci. 2014, 32, 402-410. [CrossRef]

6. Xie, M.; Bai, W.; Bai, L.; Sun, X.; Lu, Q.; Yan, D.; Qiao, Q. Life cycle assessment of the recycling of Al-PE (a laminated foil made from polyethylene and aluminum foil) composite packaging waste. J. Clean. Prod. 2016, 112, 4430-4434. [CrossRef]

7. Lee, H.J.; Lee, H.K.; Lim, E.; Song, Y.S. Synergistic effect of lignin/polypropylene as a compatibilizer in multiphase eco-composites. Compos. Sci. Technol. 2015, 118, 193-197. [CrossRef]

8. Sudár, A.; Burgstaller, C.; Renner, K.; Móczó, J.; Pukánszky, B. Wood fiber reinforced multicomponent, multiphase PP composites: Structure, properties, failure mechanism. Compos. Sci. Technol. 2014, 103, $106-112$. [CrossRef]

9. Arsalan, M.; Zeeshan, M. Comparison of physicochemical and electrochemical characterization of PVC incorporated ZT and ZM composite membranes and their applicability on TMS theoretical equation. J. Mol. Struct. 2015, 1098, 355-364. [CrossRef]

10. Wang, K.-T.; He, Y.; Song, X.-L.; Cui, X.-M. Effects of the metakaolin-based geopolymer on high-temperature performances of geopolymer/PVC composite materials. Appl. Clay Sci. 2015, 114, 586-592. [CrossRef]

11. Pajoumshariati, S.R.; Azizi, M.; Wesner, D.; Miller, P.G.; Shuler, M.L.; Abbaspourrad, A. Microfluidic-Based Cell-Embedded Microgels Using Nonfluorinated Oil as a Model for the Gastrointestinal Niche. ACS Appl. Mater. Interfaces 2018, 10, 9235-9246. [CrossRef]

12. Leach, J.B.; Schmidt, C.E. Characterization of protein release from photocrosslinkable hyaluronic acid-polyethylene glycol hydrogel tissue engineering scaffolds. Biomaterials 2005, 26, 125-135. [CrossRef]

13. Sarasam, A.; Madihally, S.V. Characterization of chitosan-polycaprolactone blends for tissue engineering applications. Biomaterials 2005, 26, 5500-5508. [CrossRef]

14. Chen, W.; Shen, H.; Zhu, X.; Yao, H.; Wang, W. Preparation and photochromic properties of PEG-400 assisted WO 3-TiO 2-ZnO composite films. Ceram. Int. 2015, 41, 14008-14012. [CrossRef]

15. Maier, C.; Calafut, T. Polypropylene: the Definitive User's Guide and Databook; William Andrew: Amsterdam, The Netherlands, 1998.

16. Risite, H.; Oualid, H.A.; Mabrouk, K.E. Effects of Vinyltriethoxysilane and Maleic Anhydride Grafted Polypropylenes on the Morphological, Thermal, Rheological, and Mechanical Properties of Polypropylene/Clay Nanocomposites. Proceedings 2018, 3, 5500. [CrossRef]

17. Weng, Y.-X.; Jin, Y.-J.; Meng, Q.-Y.; Wang, L.; Zhang, M.; Wang, Y.-Z. Biodegradation behavior of poly (butylene adipate-co-terephthalate)(PBAT), poly (lactic acid)(PLA), and their blend under soil conditions. Polym. Test. 2013, 32, 918-926. [CrossRef]

18. Salehiyan, R.; Yussuf, A.; Hanani, N.F.; Hassan, A.; Akbari, A. Polylactic acid/polycaprolactone nanocomposite: Influence of montmorillonite and impact modifier on mechanical, the rmal, and morphological properties. J. Elastom. Plast. 2015, 47, 69-87. [CrossRef] 
19. Arrieta, M.P.; López, J.; Ferrándiz, S.; Peltzer, M.A. Characterization of PLA-limonene blends for food packaging applications. Polym. Test. 2013, 32, 760-768. [CrossRef]

20. Stoehr, N.; Baudrit, B.; Haberstroh, E.; Nase, M.; Heidemeyer, P.; Bastian, M. Properties and weldability of plasticized polylactic acid films. J. Appl. Polym. Sci. 2014, 131. [CrossRef]

21. Zare, Y.; Garmabi, H.; Rhee, K.Y. Prediction of complex modulus in phase-separated poly (lactic acid)/poly (ethylene oxide)/carbon nanotubes nanocomposites. Polym. Test. 2018, 66, 189-194. [CrossRef]

22. You, J.; Lou, L.; Yu, W.; Zhou, C. The preparation and crystallization of long chain branching polylactide made by melt radicals reaction. J. Appl. Polym. Sci. 2013, 129, 1959-1970. [CrossRef]

23. Polu, A.R.; Rhee, H.-W. Nanocomposite solid polymer electrolytes based on poly (ethylene oxide)/POSS-PEG $(\mathrm{n}=13.3)$ hybrid nanoparticles for lithium ion batteries. J. Ind. Eng. Chem. 2015, 31, 323-329. [CrossRef]

24. Raja, M.; Ryu, S.H.; Shanmugharaj, A. Thermal, mechanical and electroactive shape memory properties of polyurethane (PU)/poly (lactic acid)(PLA)/CNT nanocomposites. Eur. Polym. J. 2013, 49, 3492-3500. [CrossRef]

25. Gorrasi, G.; Sorrentino, A. Photo-oxidative stabilization of carbon nanotubes on polylactic acid. Polym. Degrad. Stab. 2013, 98, 963-971. [CrossRef]

26. Hassan, A.; Balakrishnan, H.; Akbari, A. Polylactic Acid Based Blends, Composites and Nanocomposites, Advances in Natural Polymers; Springer: Berlin/Heidelberg, Germany, 2013; pp. 361-396.

27. Mohapatra, A.K.; Mohanty, S.; Nayak, S.K. Effect of PEG on PLA/PEG blend and its nanocomposites: A study of thermo-mechanical and morphological characterization. Polym. Compos. 2014, 35, 283-293. [CrossRef]

28. Choudhary, P.; Mohanty, S.; Nayak, S.K.; Unnikrishnan, L. Poly(L-lactide)/polypropylene blends: Evaluation of mechanical, the rmal, and morphological characteristics. J. Appl. Polym. Sci. 2011, 121, 3223-3237. [CrossRef]

29. Li, Y.; Han, C.; Zhang, X.; Xu, K.; Bian, J.; Dong, L. Poly (L-lactide)/Poly (D-lactide)/clay nanocomposites: Enhanced dispersion, crystallization, mechanical properties, and hydrolytic degradation. Polym. Eng. Sci. 2014, 54, 914-924. [CrossRef]

30. Wu, C.-S.; Liao, H.-T. A new biodegradable blends prepared from polylactide and hyaluronic acid. Polymer 2005, 46, 10017-10026. [CrossRef]

31. Girdthep, S.; Worajittiphon, P.; Molloy, R.; Lumyong, S.; Leejarkpai, T.; Punyodom, W. Biodegradable nanocomposite blown films based on poly (lactic acid) containing silver-loaded kaolinite: A route to controlling moisture barrier property and silver ion release with a prediction of extended shelf life of dried longan. Polymer 2014, 55, 6776-6788. [CrossRef]

32. Muthuraj, R.; Misra, M.; Mohanty, A.K. Biodegradable compatibilized polymer blends for packaging applications: A literature review. J. Appl. Polym. Sci. 2018, 135, 45726. [CrossRef]

33. Liu, X.; Gao, C.; Sangwan, P.; Yu, L.; Tong, Z. Accelerating the degradation of polyolefins through additives and blending. J. Appl. Polym. Sci. 2014, 131. [CrossRef]

34. Ploypetchara, N.; Suppakul, P.; Atong, D.; Pechyen, C. Blend of polypropylene/poly (lactic acid) for medical packaging application: physicochemical, the rmal, mechanical, and barrier properties. Energy Procedia 2014, 56, 201-210. [CrossRef]

35. Tjong, S.C.; Xu, S.A.; Mai, Y.W. Impact-specific essential work of fracture of maleic anhydride-compatibilized polypropylene/elastomer blends and their composites. J. Polym. Sci. Part B Polym. Phys. 2002, 40, 1881-1892. [CrossRef]

36. Xu, S.A.; Tjong, S.C. Effect of compatibilizer content on the tensile properties and fracture toughness of high density polyethylene/polystyrene blends. Polym. J. 2000, 32, 208. [CrossRef]

37. Ebadi-Dehaghani, H.; Khonakdar, H.A.; Barikani, M.; Jafari, S.H. Experimental and theoretical analyses of mechanical properties of PP/PLA/clay nanocomposites. Compos. Part B Eng. 2015, 69, 133-144. [CrossRef]

38. Lin, S.; Guo, W.; Chen, C.; Ma, J.; Wang, B. Mechanical properties and morphology of biodegradable poly (lactic acid)/poly (butylene adipate-co-terephthalate) blends compatibilized by transesterification. Mater. Des. (1980-2015) 2012, 36, 604-608. [CrossRef]

39. Frackowiak, S.; Ludwiczak, J.; Leluk, K.; Orzechowski, K.; Kozlowski, M. Foamed poly (lactic acid) composites with carbonaceous fillers for electromagnetic shielding. Mater. Des. (1980-2015) 2015, 65, 749-756. [CrossRef]

40. Rasal, R.M.; Janorkar, A.V.; Hirt, D.E. Poly (lactic acid) modifications. Prog. Polym. Sci. 2010, 35, 338-356. [CrossRef] 
41. Spitalsky, Z.; Tasis, D.; Papagelis, K.; Galiotis, C. Carbon nanotube-polymer composites: Chemistry, processing, mechanical and electrical properties. Prog. Polym. Sci. 2010, 35, 357-401. [CrossRef]

42. Dintcheva, N.T.; la Mantia, F.; Malatesta, V. Photo-oxidation behaviour of polyethylene/multi-wall carbon nanotube composite films. Polym. Degrad. Stab. 2009, 94, 162-170. [CrossRef]

43. Liu, Y.-L.; Chang, Y.-H.; Liang, M. Poly (2, 6-dimethyl-1, 4-phenylene oxide)(PPO) multi-bonded carbon nanotube (CNT): Preparation and formation of PPO/CNT nanocomposites. Polymer 2008, 49, 5405-5409. [CrossRef]

44. Martone, A.; Faiella, G.; Antonucci, V.; Giordano, M.; Zarrelli, M. The effect of the aspect ratio of carbon nanotubes on their effective reinforcement modulus in an epoxy matrix. Compos. Sci. Technol. 2011, 71, 1117-1123. [CrossRef]

45. Lee, B.H.; Cho, J.W.; Kim, K.H. Crystallization, orientation, and mechanical properties of laser-heated photothermally drawn polypropylene/multi-walled carbon nanotube fibers. Eur. Polym. J. 2017, 91, 70-80. [CrossRef]

46. Bourmaud, A.; Pimbert, S. Investigations on mechanical properties of poly (propylene) and poly (lactic acid) reinforced by miscanthus fibers. Compos. Part A Appl. Sci. Manuf. 2008, 39, 1444-1454. [CrossRef]

47. Bao, S.; Tjong, S.C. Mechanical behaviors of polypropylene/carbon nanotube nanocomposites: The effects of loading rate and temperature. Mater. Sci. Eng. A 2008, 485, 508-516. [CrossRef]

48. Castellani, F.; Esposito, A.; Stanzione, V.; Altieri, R. Measuring the biodegradability of plastic polymers in olive-mill waste compost with an experimental apparatus. Adv. Mater. Sci. Eng. 2016, 2016. [CrossRef]

49. Roy, S.; Srivastava, S.K.; Pionteck, J.; Mittal, V. Mechanically and Thermally Enhanced Multiwalled Carbon Nanotube-Graphene Hybrid filled Thermoplastic Polyurethane Nanocomposites. Macromol. Mater. Eng. 2015, 300, 346-357. [CrossRef]

50. Boussaboun, Z.; Azizi, S.; Ouellet-Plamondon, C. Conductive clay containing graphene layers. In Proceedings of the 2017 IEEE 17th International Conference on Nanotechnology (IEEE-NANO), Pittsburgh, PA, USA, 25-28 July 2017; IEEE: Piscataway, NJ, USA, 2017; pp. 1065-1069.

51. Ren, F.; Li, Z.; Xu, L.; Sun, Z.; Ren, P.; Yan, D.; Li, Z. Large-scale preparation of segregated PLA/carbon nanotube composite with high efficient electromagnetic interference shielding and favourable mechanical properties. Compos. Part B Eng. 2018. [CrossRef]

52. Kurusu, R.S.; Helal, E.; Moghimian, N.; David, E.; Demarquette, N. The Role of Selectively Located Commercial Graphene Nanoplatelets in the Electrical Properties, Morphology, and Stability of EVA/LLDPE Blends. Macromol. Mater. Eng. 2018, 1800187. [CrossRef]

53. Lee, S.H.; Kim, M.W.; Kim, S.H.; Youn, J.R. Rheological and electrical properties of polypropylene/MWCNT composites prepared with MWCNT masterbatch chips. Eur. Polym. J. 2008, 44, 1620-1630. [CrossRef]

54. Mijović, J.; Sy, J.-W. Molecular dynamics during crystallization of poly (L-lactic acid) as studied by broad-band dielectric relaxation spectroscopy. Macromolecules 2002, 35, 6370-6376. [CrossRef]

55. Xu, P.; Luo, X.; Zhou, Y.; Yang, Y.; Ding, Y. Enhanced cold crystallization and dielectric polarization of PLA composites induced by P [MPEGMA-IL] and graphene. Thermochim. Acta 2017, 657, 156-162. [CrossRef]

56. Mai, F.; Deng, H.; Tu, W.; Chankajorn, S.; Fu, Q.; Bilotti, E.; Peijs, T. Oriented poly (lactic acid)/carbon nanotube composite tapes with high electrical conductivity and mechanical properties. Macromol. Mater. Eng. 2015, 300, 1257-1267. [CrossRef]

57. Azizi, S.; David, E.; Fréchette, M.F.; Nguyen-Tri, P.; Ouellet-Plamondon, C. Electrical and thermal conductivity of ethylene vinyl acetate composite with graphene and carbon black filler. Polym. Test. 2018. [CrossRef]

58. Azizi, S.; David, E.; Fréchette, M.F.; Nguyen-Tri, P.; Ouellet-Plamondon, C.M. Electrical and thermal phenomena in low-density polyethylene/carbon black composites near the percolation threshold. J. Appl. Polym. Sci. 2018, 47043. [CrossRef]

59. Azizi, S.; Ouellet-Plamondon, C.; David, E.; Fréchette, M. Electrical and thermal properties of low-density polyethylene/graphene-like composite. In Proceedings of the 2017 IEEE Conference on Electrical Insulation and Dielectric Phenomenon (CEIDP), Fort Worth, TX, USA, 22-25 October 2017; IEEE: Piscataway, NJ, USA, 2017; pp. 517-520.

60. Song, Z.; Xiao, H.; Zhao, Y. Hydrophobic-modified nano-cellulose fiber/PLA biodegradable composites for lowering water vapor transmission rate (WVTR) of paper. Carbohydr. Polym. 2014, 111, 442-448. [CrossRef] [PubMed] 
61. Wu, D.; Hakkarainen, M. Recycling PLA to multifunctional oligomeric compatibilizers for PLA/starch composites. Eur. Polym. J. 2015, 64, 126-137. [CrossRef]

62. De L. Freitas, A.L.P.; Filho, L.R.T.; Calvão, P.S.; de Souza, A.M.C. Effect of montmorillonite and chain extender on rheological, morphological and biodegradation behavior of PLA/PBAT blends. Polym. Test. 2017, 62, 189-195.

63. Seligra, P.G.; Lamanna, M.; Famá, L. Promising PLA-functionalized MWCNT composites to use in nanotechnology. Polym. Compos. 2016, 37, 3066-3072. [CrossRef]

64. Zeng, Y.; Zhu, Z.; Du, D.; Lin, Y. Nanomaterial-based electrochemical biosensors for food safety. J. Electroanal. Chem. 2016, 781, 147-154. [CrossRef]

(C) 2019 by the authors. Licensee MDPI, Basel, Switzerland. This article is an open access article distributed under the terms and conditions of the Creative Commons Attribution (CC BY) license (http://creativecommons.org/licenses/by/4.0/). 